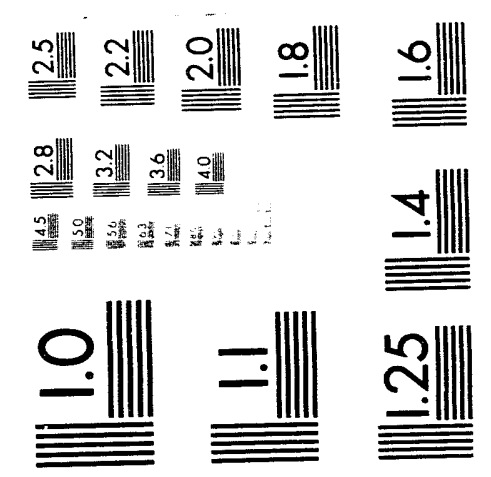



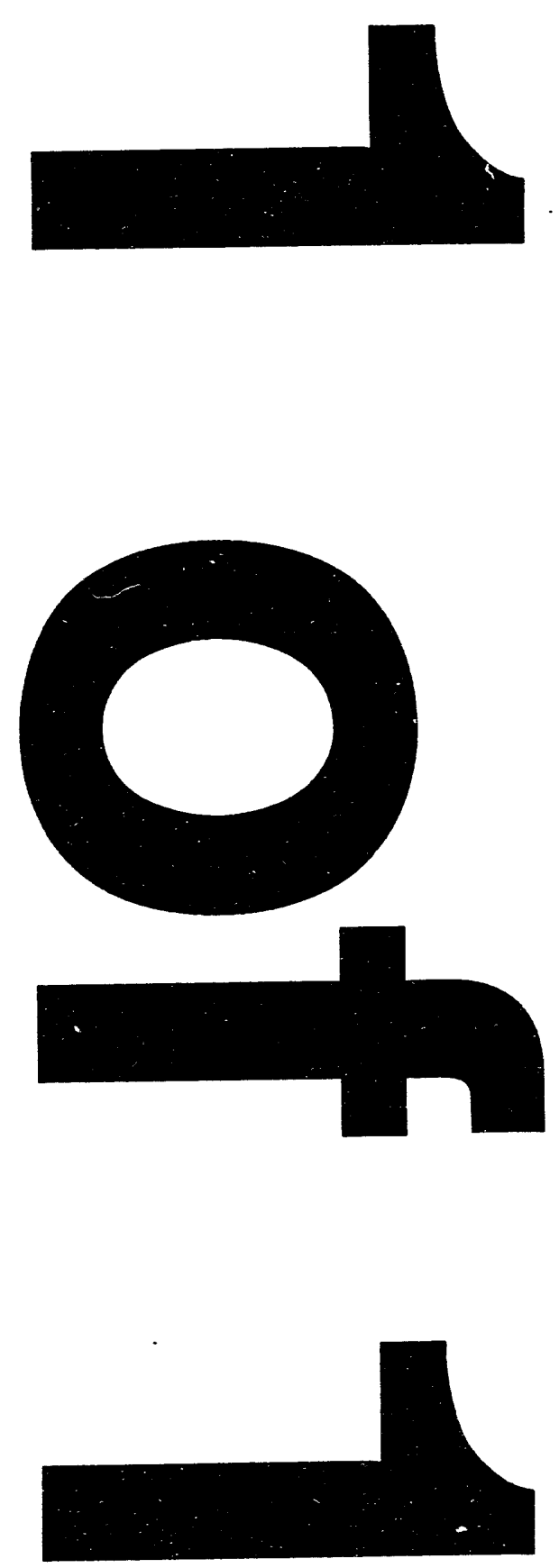
SAND94-0128

Distribution

Unlimited Release

Category UC-335

Printed January 1994

\title{
Inspection Reliability of a Nortec-30 Eddyscan System*
}

\author{
Floyd W. Spencer \\ Statistics and Human Factors Department \\ Sandia National Laboratories \\ Albuquerque, NM 87185-5800
}

\begin{abstract}
This report presents the results of an inspection around fastener holes in simulated lap splice specimens using a Nortec-30 Eddyscan inspection system. The inspector performing the tests had no prior knowledge of the extent or location of cracks in the specimens examined. The results of the inspection are presented in terms of various probability of detection curve models and are compared to various other eddy current inspections performed on the same set of test specimens. Results indicate that the system is capable, with high confidence, of detecting 60 to 70 mil cracks from under countersink fasteners.
\end{abstract}

\footnotetext{
* This work was performed for the Federal Aviation Administration (FAA) Technical Center under US Department of Transportation Contract DTFA-03-91-A-0018. This document is currently under review by the FAA Flight Standards Office for possible publication by the Department of Transportation.
}

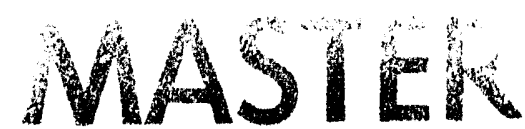




\section{Introduction}

The Nortec-30 Eddyscan inspection system is designed for testing fastener holes with the fastener in place. To evaluate its reliability, the system was used to inspect simulated Boeing lap splice joints. The extent and location of cracks in the upper skins were unknown to the inspector using the equipment. The results of the experiment are discussed in this report in terms of probability of detection curves. Comparisons are made to baseline laboratory detection data obtained using other eddy current equipment.

This report is organized into four sections. Section 1 contains a brief product description. Section 2 discusses the conditions surrounding the experiment and the setup procedures followed in performing the experiment. Results of the inspection are presented in the form of probability of detection (POD) curves and relative operating characteristic (ROC) curves in Section 3. A summary and a discussion of the results are given in section 4 .

\section{Product Description}

The following brief description of the Nortec-30 Eddyscan system is condensed from product description information available from Staveley Instruments, Inc. This description is meant to reflect the basic technology and capabilities of the instrument. It is not a complete description of all the capabilities of the instrument.

The Nortec-30 Eddyscan System is designed for testing fastener holes with the fastener in place. It consists of a portable instrument with an accompanying small hand-held scanner. The instrument uses pulsed eddy current techniques and a broadband Hall effect sensor.

The scanner is centered over the fastener during the inspection. The scanner rotates the Hall effect sensor and the driving coil about the fastener. Eddy currents are induced by the coil into the test surface. The induced signal is a sharp edged magnetic pulse that provides excitation for a wide range of frequencies. Due to phase velocity effects, the lower frequency components propagate through the material at slower rates than do the higher frequency components.

As a result of the differences in propagation times, effects from defects that are shallower appear earlier on the detected waveform. A "gate" of a certain width is set to start a certain time after the start of each pulse. The width and start time of the gate are set by the user and are determined with test standards. The outputs for a particular gate are arranged sequentially. If there are no flaws and the scanner is perfectly centered, the resulting outputs would form a straight line. The presence of a flaw will alter the signal as the Hall sensor passes. This will cause a "bump" to appear in the baseline signal. By adjusting the gate parameters and the gain applied to the signal, the instrument sensitivity can be altered for both flaw depth and size.

If the Hall sensor is not exactly centered over a circular fastener, the distance between the edge of the fastener and the sensor will vary sinusoidally. If the changes in distance are relatively small, the off-center probe signal will also be roughly sinusoidal. The frequency of the sine wave will be the rotation frequency of the scanner. Thus, when the scanner is close to being centered, the remaining off-center signal can be removed by subtracting the appropriate sine wave. 
The "off-center" signal is not totally discarded. It is used to aid in positioning the scanner over the fastener. First the signal is filtered. Then the phase angle of the peak is used to derive offcenter direction and the amplitude of the signal is used to determine the distance from the center. This information is then used to drive a cross-hair on the display showing relative positioning.

The instrument has been designed to have three (3) modes during operation. These are:

1. Free running operation

2. Search for center

3. "Frozen" analysis display

In the free running operation the raw data from the scanner are displayed on the screen. The offcenter data and centering cross-hairs are also displayed. Displays are updated as the scanner moves across a fastener. Upon pressing the [TEST] button on the instrument, the search for center mode is entered. This mode differs from the free running mode in that the instrument is checking that the cross-hair is less than a certain distance from the origin. "Close enough" is represented by a circle on the cross-hair display. The actual off-center distance is determined by the gain setting on the centering gate.

The instrument will switch to a frozen analysis display once the cross-hair stays in the circle for about 1 second. It is at this time that the off-center data are removed from the signal and the processed data are shown on the screen. A threshold can be set as a percentage of full scale. If an inspection results in a signal that exceeds this threshold then an alarm wiil alert the operator.

\section{Experimental Conditions}

\section{Test Specimens}

The experiment was conducted on forty-three (43) small specimens and two (2) large panels, all with simulated lap splices. Each of the small panels contains 20 inspection sites. The large panels each contain 102 inspection sites. Thus, 1064 rivets were examined. Flaws were introduced into the sites as described in the following paragraphs. (Details are given in reference [1].)

The small specimens measure twenty inches by twenty inches. They contain two sheets of .040 inch thick 2024 T-3 clad aluminum. Flaws were grown in the top sheet before the sheets were joined as a lap splice. The flaws were grown by fatigue cycling aluminum plates with undersize holes and starter cuts at the desired locations. All signs of the starter cuts were removed when the specimens were drilled to dimensions for joining as lap splices. See Figure 1.

The large panels are eight and one half $\left(8 \frac{1}{2}\right)$ feet long and approximately four (4) feet wide. These panels contain a single lap splice joint with all the frame structure behind the skins that would be in place in a typical Boeing narrow body aircraft such as the 727 or 737 . The flaws in these panels were grown through fatigue cycling. This was done on a special test bed that simulated the fuselage bi-axial pressure induced stress typically encountered in one flight cycle. Details about the test specimen structure can be found in Reference 1.

The surfaces of all the small specimens and one of the two large panels were painted with a typical aircraft paint. The surface of the second large panel was bare aluminum. The experiment was 
started with a thin transparent 3 mil tape over the inspection sites on the small specimens. This tape had been used to protect the surface from being scratched by probes and thereby providing visual clues to subsequent inspectors. However, small air bubbles beneath the tape were found to be affecting the inspections. The inspection probe on the Nortec-30 did not make surface contact with the specimen during the rotation of the sensors. Therefore, the tape was removed, as it was slowing the inspection and it was determined that no adverse marring of the surface would occur.

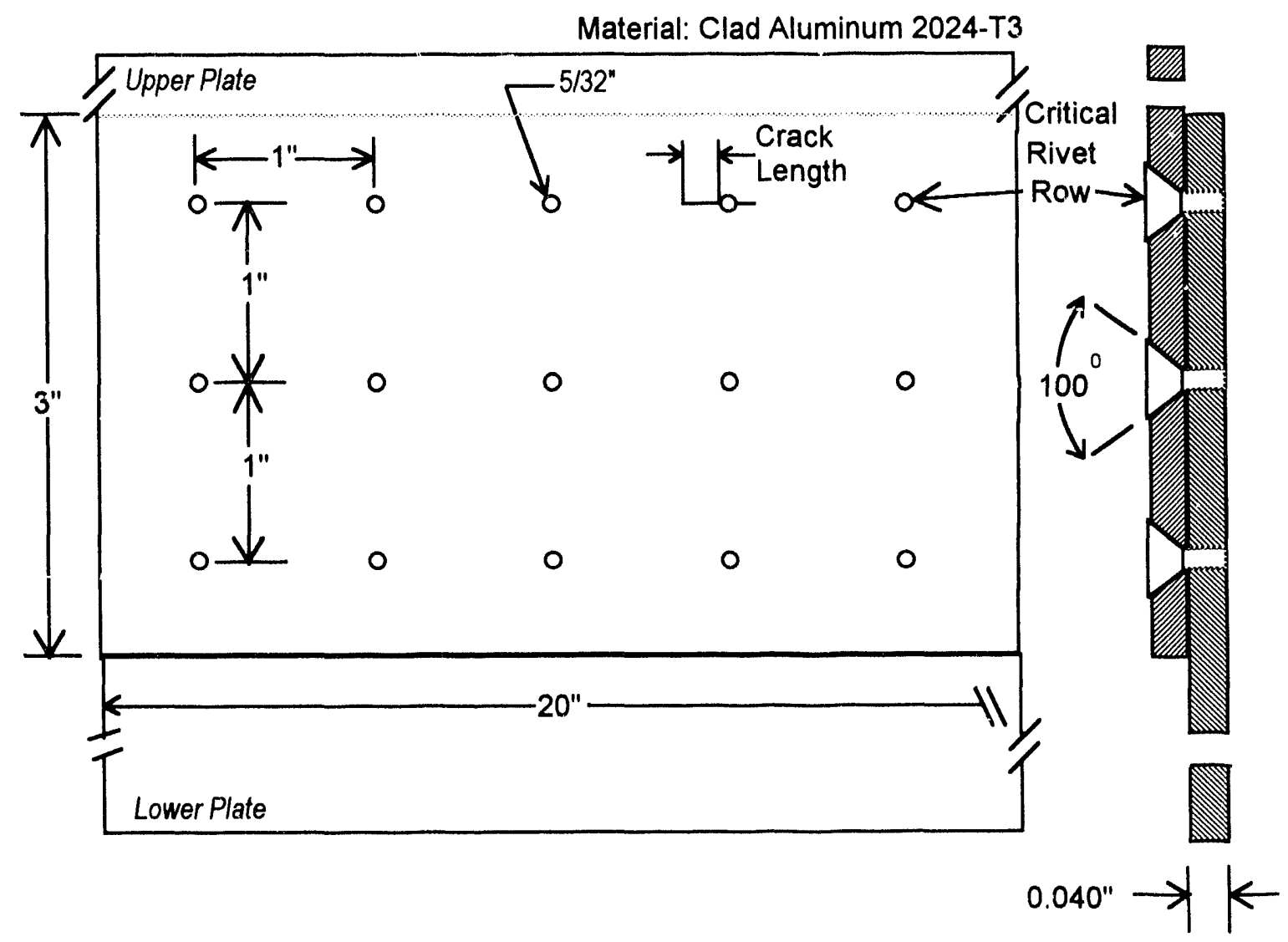

Figure 1 Schematic of small specimens 


\section{Inspection Equipment Setup}

The inspections using the Nortec-30 were performed by the Eddy Current Product Manager from Staveley Instruments, Inc. The inspector set up the equipment using a Boeing Reference Standard \#369 supplied by the AANC. The Boeing \#369 standard contains an EDM notch that extends 0.100 inches from the edge of the countersink. The initial setup was checked against a standard in the possession of the inspector. This second standard had a 0.060 inch flaw. The setup was modified slightly to enhance the indication for this smaller flaw.

The resulting setup parameters were:

$\begin{array}{lr}\text { Gain } & 28.5 \mathrm{~dB} \\ \text { Gate start } & 100 \mathrm{~ms} \\ \text { Gate width } & 30 \mathrm{~ms} \\ \text { Alarm level } & \text { not used } \\ \text { Rotation } & 354^{\circ}\end{array}$

For all inspections, the inspector was asked to use a 3-point subjective rating scale. A rating of 3 would mean that the inspector is certain that there is a reportable flaw indication. A rating of 2 indicates a reasonable certainty that a call of a flaw being present is correct. A rating of 1 is used to indicate the perception of a signal, but some doubt about the indication actually being reportable. For this inspection, the rating of 1 was applied to those signals that the inspector used such descriptions as, "There seems to be a signal, although at the current sensitivity level it would probably be passed by."

The inspector gave locations for all flaw indications. A monitor was present during the inspection and recorded the calls as they were being made. The inspection of the 820 sites $(20 \times 43)$ on the small panels was done in a laboratory on a table top with the equipment operating on standard $110 \mathrm{AC}$ wall current. The inspection of the 204 sites $(102 \times 2)$ on the large panels was done in the hangar with the Nortec-30 operating from batteries. The large panels were hanging vertically, simulating the fuselage of an aircraft.

\section{Inspection Results}

The 43 small panels were inspected in a five (5) hour period that included approximately one and one half $\left(1 \frac{1}{2}\right)$ hours for lunch and other breaks. The large panels were inspected in fifty (50) minutes. The individual site (rivet) inspections, in general, took between 6 and 20 seconds, with an overall average of approximately 14 seconds per inspection site.

\section{Relative Operating Characteristics}

A summary of the results of the inspection is giver in Table 1. In Table 1, flaws are grouped into three categories which correspond to being under the rivet head $(<50 \mathrm{mils})$, out from the rivet edge but less than the setup standard (50 to $100 \mathrm{mils}$ ), and larger than the setup standard ( $>100$ mils).

Figure 2 presents the data of Table 1 in the form of empirical relative operating characteristic curves. The points of the curves are the proportion of detects in each of the categories versus the 
false call rate. The first point of each curve is based on the strictest of criterion levels, that is the "3s." The second poini shows how the detection rate varies when the criterion for making a call is relaxed, as is reflected by considering the " $3 \mathrm{~s}$ " and the " $2 \mathrm{~s}$." The third point reflects the most lenient criteria by incorporating the " $1 \mathrm{~s}$ " into the detection level.

Table 1. Summary of Inspection Results

\begin{tabular}{|l|r|r|r|r|r|}
\hline & No Call & " $1 \mathrm{~s} "$ & " $2 \mathrm{~s} "$ & " $3 \mathrm{~s}^{\prime}$ & Totals \\
\hline *Non-flawed sites & 688 & 13 & 4 & 3 & 708 \\
\hline$<0.050$ inch flaws & 25 & 11 & 5 & 6 & 47 \\
\hline 0.050 to 0.100 inch flaws & 3 & 0 & 4 & 86 & 93 \\
\hline$>0.100$ inch flaws & 0 & 0 & 0 & 144 & 144 \\
\hline
\end{tabular}

*small specimens only

\section{Relative Operating Characteristics}

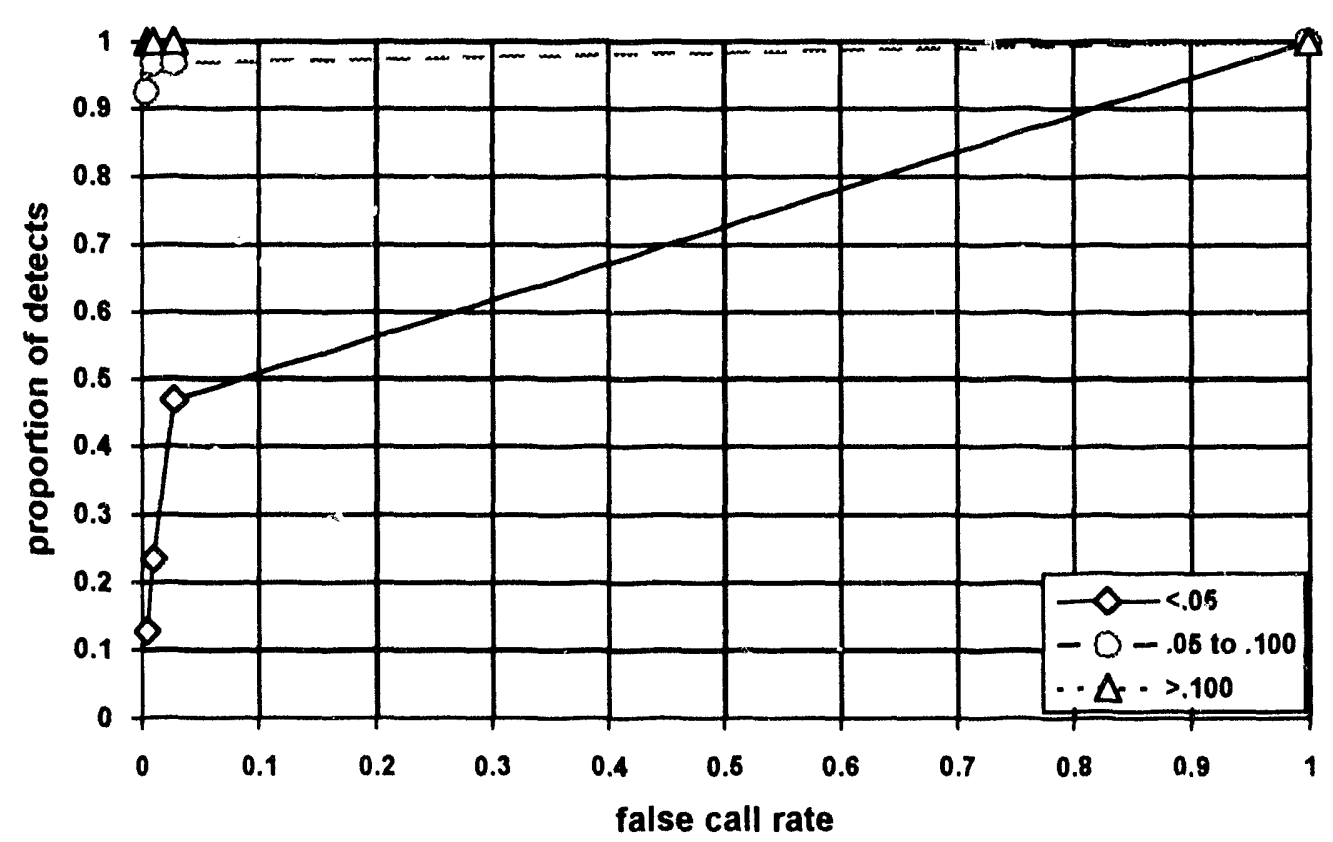

Figure 2. Empirical Relative Operating Characteristic Curve 


\section{Probability of Detection Curves}

For the purposes of quantifying the probability of detection, curves are fit to the results (detect or miss) of the inspection for the known flaws. Four different mathematical fits are given for the data in Figures 3 through 5. Figure 3 presents the curves fit to the "sure" calls (3's). Figure 4 presents the fitted curves for the detects with ratings of 3 or 2 . Similarly, in Figure 5 those curves fitting the most lenient criterion used (1's, 2's, and 3's) are given. False call rates (FCR) are given as the percentage of unflawed rivets where calls were made.

The curves that were fit to the data, as a function of the natural logarithm of the crack length, $a$, are:

$$
\begin{array}{lr}
(1 / \sqrt{2 \pi}) \int_{-\infty}^{\alpha+\beta \cdot \ln (a)} \exp \left(-z^{2} / 2\right) d z & \text { (Normal) } \\
1 /(1+\exp (-\{\alpha+\beta \ln (a)\})) & \text { (Logistic) } \\
1-\exp (-\exp (\alpha+\beta \ln (a)) & (\text { Gompertz[1]) } \\
\exp (-\exp (\alpha+\beta \ln (a)) & \text { (Gompertz[0]). }
\end{array}
$$

The parameters, $\alpha$ and $\beta$, were estimated using maximum likelihood methods applied to binary response data as implemented by the $\mathrm{SAS}^{\circledR}$ procedure Probit. The regression type models for binary data can be applied to the occurrence of either event, detect or miss. The symmetry of the Normal distribution guarantees that the fitted curve for the probability of detection is independent of whether one fits a curve to the detects or fits a curve to the probability of misses and then takes the complement. The parameters, $\alpha$ and $\beta$, will differ in sign, but will have the same magnitude. The same is true for the Logistic distribution. The Gompertz distribution, however, does not have that symmetry. The result of fitting the Gompertz distribution $\{1-\exp (-\exp (\mathrm{x})\}$ to the probability of detection is denoted Gompertz(1). The result of fitting the same distribution to the probability of non-detection and taking the complement is denoted as Gompertz(0).

There is no inherent reason why one curve should be adopted over another. The different forms are given here to illustrate variation present from the choice of representation. The Logistic and the Normal curves are very similar and are the most prevalent in use. The Normal curves for the 3 different Nortec 30 criterion levels are repeated in Figure 6. They are compared with similar curve fits to laboratory inspection data gathered using sliding probe and template procedures [2]. The backgrounds on those inspections are given in Table 2.

All curves presented to this point have been best fit (maximum likelihood) curves. In Figure 7, lower $95 \%$ confidence curves are given for the probabilities of detection for selected curves. All the fits in Figure 7 are for the Normal form of the distribution. The curves not shown have similar shifts in the lower confidence curve compared to the curve of best fit. 
Probability of Detection Curves - Nortec 30

(3 Calls - FCR $=.4 \%$ )

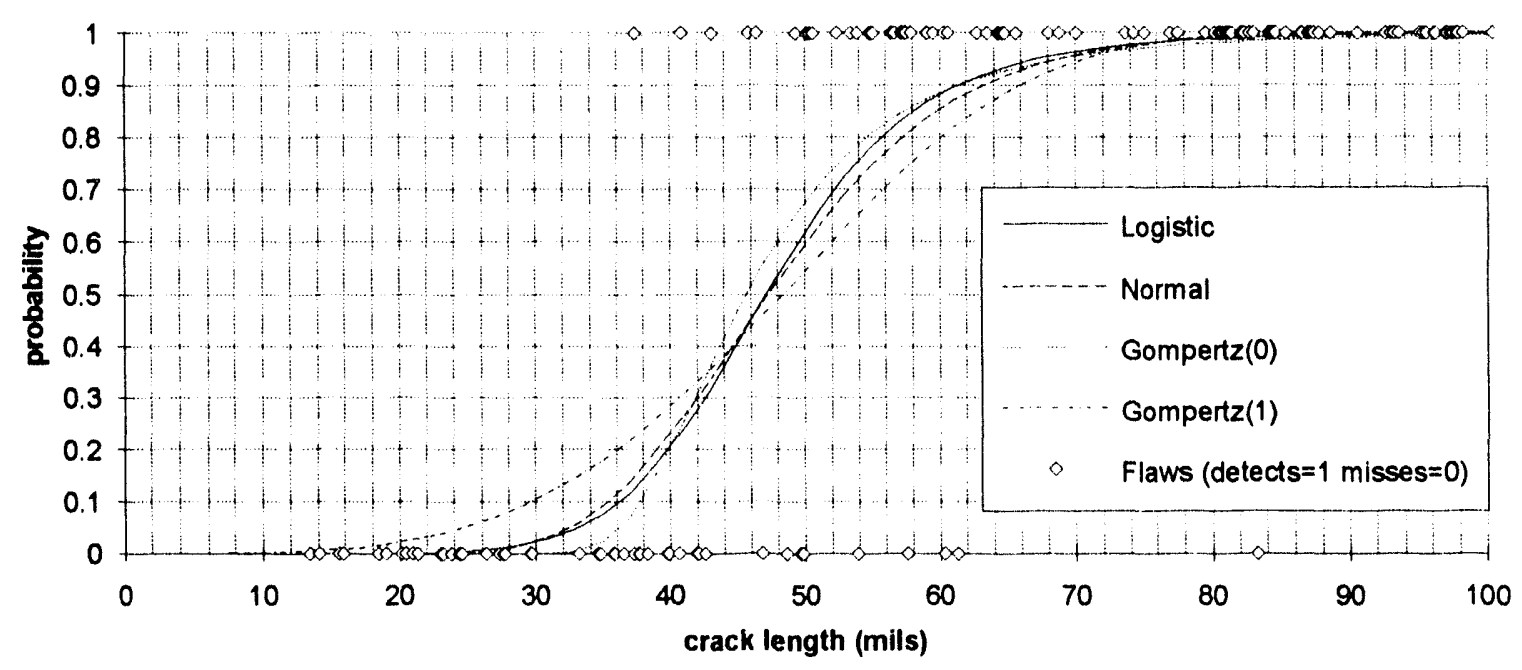

Figure 3. Probability of Detection curves for most stringent criteria (false call rate at .4\%).

\section{Probability of Detection Curves - Nortec 30}

$(3,2$ Calls - FCR $=1.0 \%)$

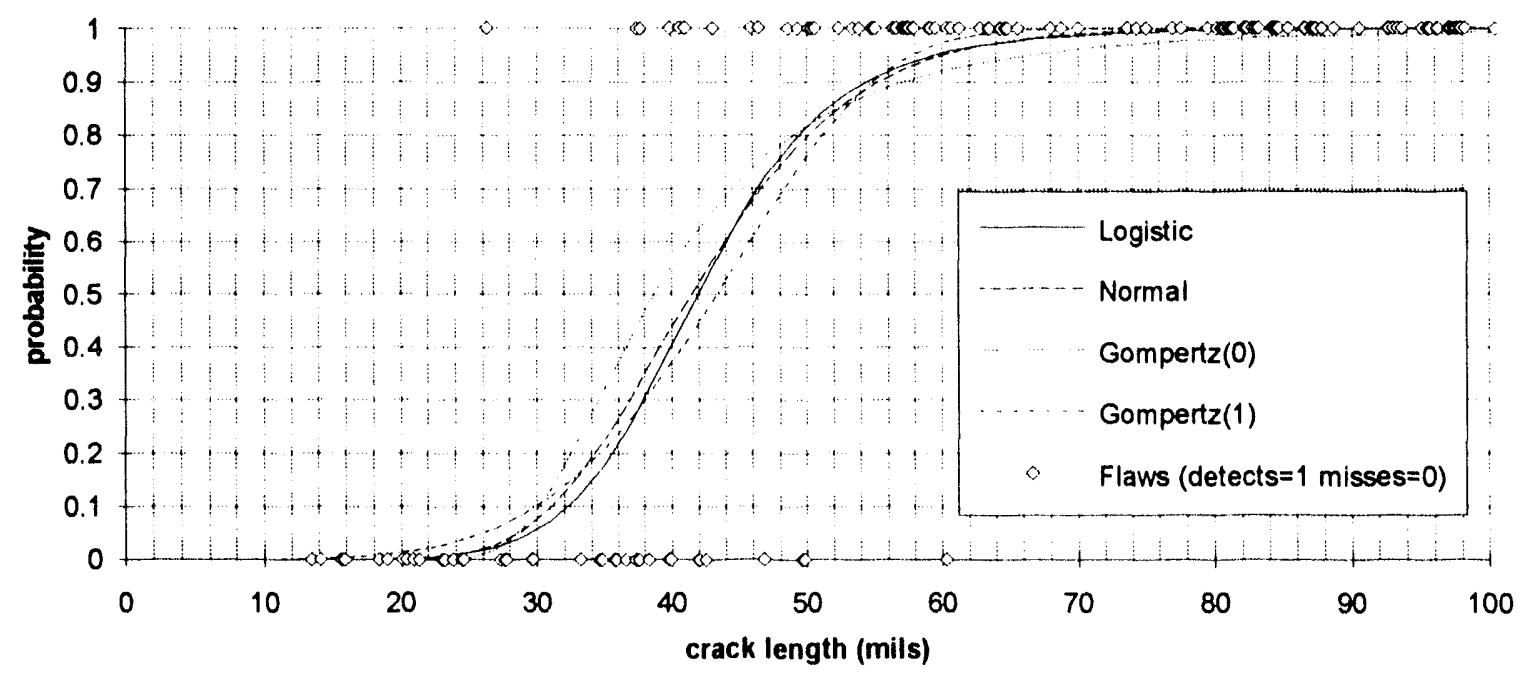

Figure 4. Probability of Detection curves for less stringent criteria (false call rate at $1.0 \%$ ). 
Probability of Detection Curves - Nortec 30

$(3,2,1$ Calls $-F C R=2.8 \%)$

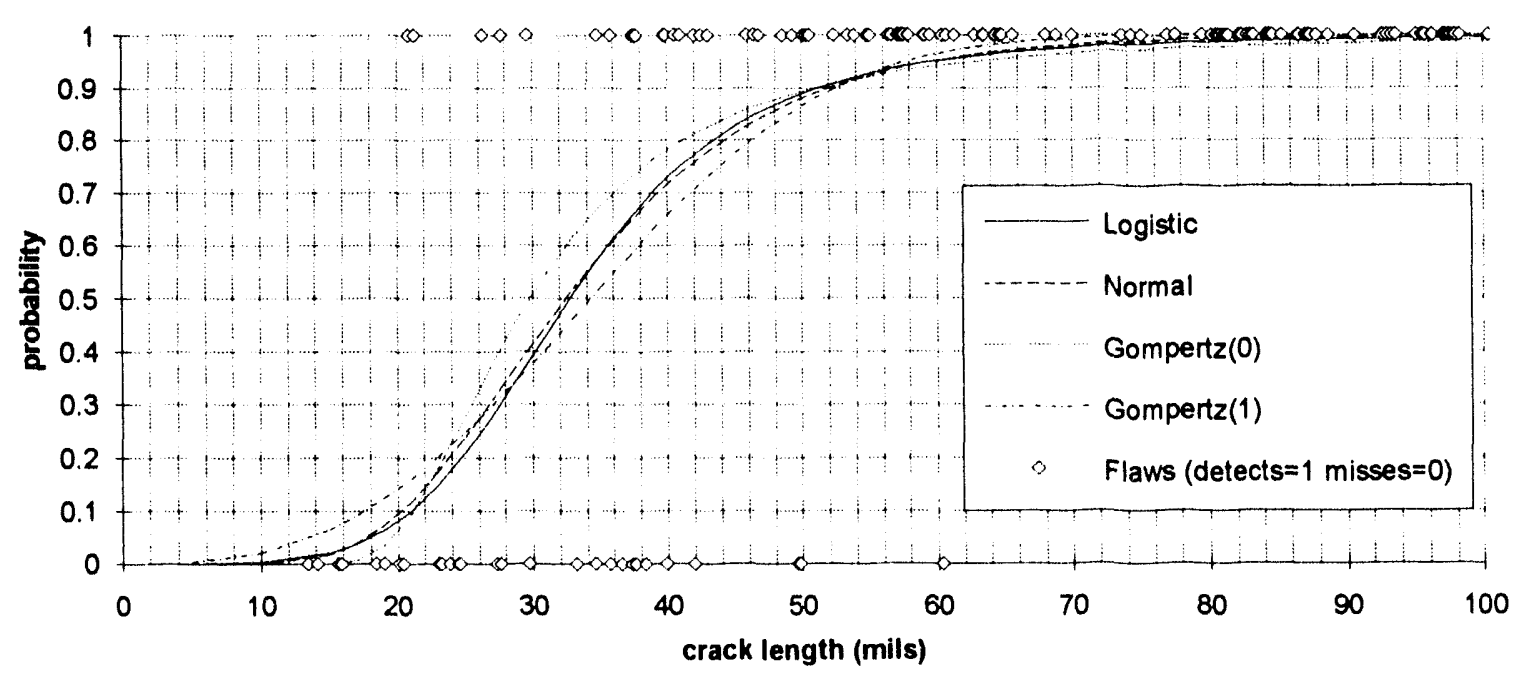

Figure 5. Probability of Detection curves for relaxed criteria (false call rate at $2.8 \%$ ).

\section{Comparison of Nortec 30 (N-30) to Other Eddy Current Inspections}

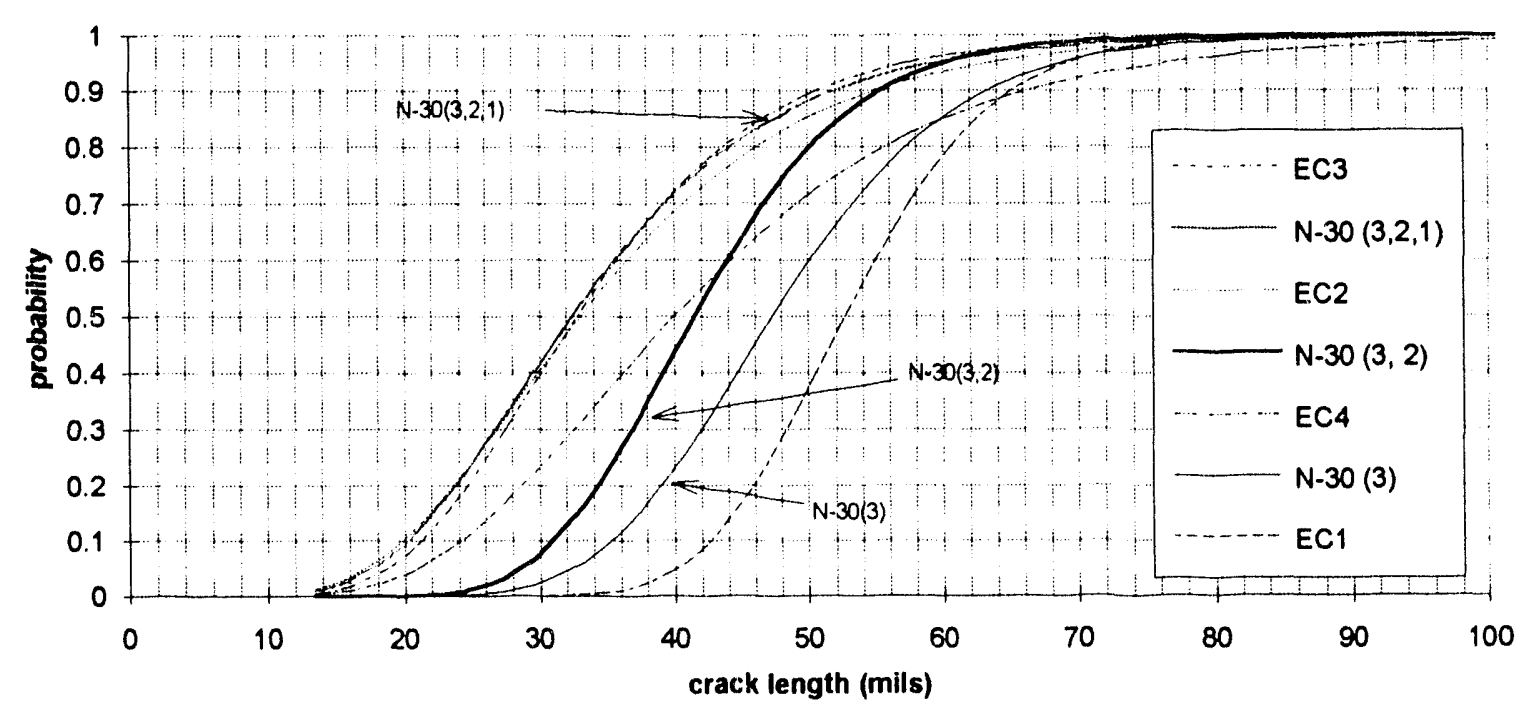

Figure 6. Nortec 30 compared to other eddy current inspections Legend order is from largest to smallest probability at 50 mils. All curves are Normal fits. 


\section{Selected Probability of Detection Curves}

with 95\% Lower Confidence Bounds

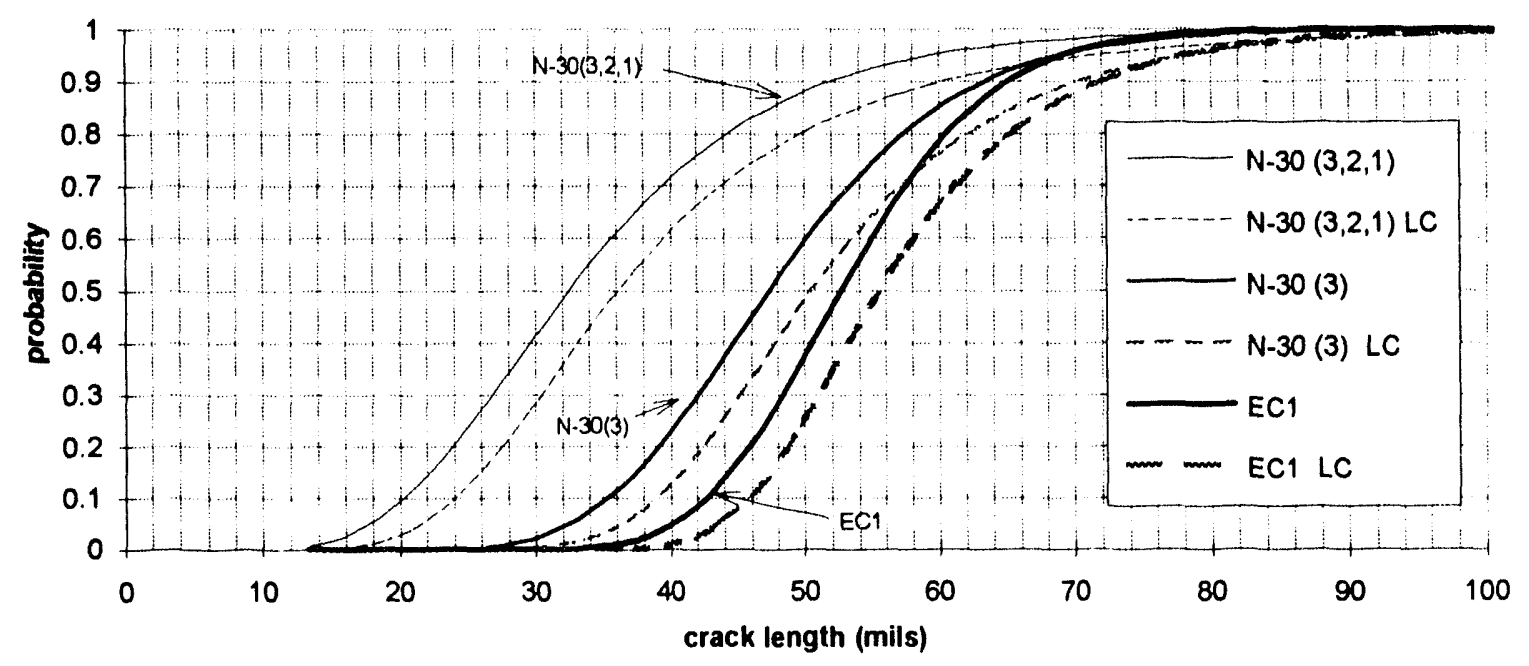

Figure 7. Lower 95\% Confidence Curves for Selected Normal PoD fits. Similar shifts occur for cases not shown.

Table 2. Background on Reference 2 Laboratory Inspections. All used Rohmann Elotest B2.

\begin{tabular}{|l|l|l|c|}
\hline Inspection & \multicolumn{1}{|c|}{ Qualifications } & \multicolumn{1}{|c|}{ Procedure } & $\begin{array}{c}\text { False Call } \\
\text { Rate (\%) }\end{array}$ \\
\hline $\mathrm{EC1}$ & $\begin{array}{l}\text { NDT Level III, Supervisor and } \\
\text { Examiner - >25 years aircraft experience }\end{array}$ & Sliding probe $-16 \mathrm{kHz}$ & .9 \\
\hline $\mathrm{EC} 2$ & $\begin{array}{l}\text { NDT Level III, ASNT Level III - }>25 \\
\text { years in NDT training }\end{array}$ & Template $-20 \mathrm{kHz}$ & .3 \\
\hline $\mathrm{EC} 3$ & $\begin{array}{l}\text { ASNT Level III - >18 years in NDT } \\
\text { training and development }\end{array}$ & Template $-30 \mathrm{kHz}$ & .3 \\
\hline EC4 & $\begin{array}{l}\text { ASNT Level II - 13 years experience in } \\
\text { NDT inspection and development }\end{array}$ & Template $-30 \mathrm{kHz}$ & .9 \\
\hline
\end{tabular}




\section{Summary and Discussion}

The reported inspection results represent a single inspector using the Nortec 30 Eddyscan. The inspector was an Eddy Current Product Manager from Staveley Instruments, Inc. and was well versed with the use of the instrument.

The inspector gave subjective ratings to the various calls. The relative steep relative operating characteristic curve (Figure 2) for the class of flaws less than 0.050 inches in length indicates the presence of signal above background noise. Half of the flaws detected in this category were rated as " $1 \mathrm{s.}$." In these cases the inspector expressed the opinion that a signal was likely present but that the initial setup (on a 0.100 inch flaw) was not sensitive enough to give a clear indication.

All flaws greater than 0.100 inches in length were detected. The largest flaw missed, smallest flaw detected, .90 probability fit, and flaw size for which the lower $95 \%$ confidence interval on probability of detection exceeds 0.9 for each criteria level are given in the following table. The latter two values are estimated using the Normal distribution function.

\begin{tabular}{|l|c|c|c|c|}
\hline \multicolumn{1}{|c|}{ Criterion Level } & $\begin{array}{c}\text { Largest } \\
\text { flaw missed } \\
\text { (mils) }\end{array}$ & $\begin{array}{c}\text { Smallest Flaw } \\
\text { detected } \\
\text { (mils) }\end{array}$ & $\begin{array}{c}\text { Flaw length for } \\
.90 \text { pod -- } \\
\text { Normal fit }\end{array}$ & $\begin{array}{c}\text { Flaw length for which } \\
\text { lower 95\% conf. int. } \\
\text { for pod is }>.9\end{array}$ \\
\hline \hline $\begin{array}{l}\text { Stringent } \\
(3 \text { 's, FCR }=.4 \%)\end{array}$ & 83 & 37 & 63 & 70 \\
\hline $\begin{array}{l}\text { Moderate } \\
(3,2 \text { 's, FCR }=1.0 \%)\end{array}$ & 60 & 26 & 55 & 62 \\
\hline $\begin{array}{l}\text { Lenient } \\
(3,2,1 \text { 's, FCR }=2.8 \%)\end{array}$ & 60 & 21 & 52 & 60 \\
\hline
\end{tabular}

Using the most stringent criterion, the Nortec 30 inspection achieved better probability of detection than was achieved using a sliding probe. At the moderate criterion level, the false call rates for the Nortec 30 are comparable to that obtained with the sliding probe but with an approximate shift in probability of detection curves of 10 mils (compare ECl of Figure 6.)

With the most lenient criterion level, the Nortec 30 probability of detection curve is almost identical with that fit to the highly qualified inspectors using template and pencil probe (EC2 and EC3 of Figure 6). However, the false call rate was almost 3\% as compared to $0.3 \%$ achieved with the template procedures.

The ability of the Nortec 30 Eddyscan system to use the "off center" signal to give direct feedback on centering the probe was a time-saver. No appreciable time differences were observed in inspecting the painted large panel versus the unpainted large panel. However, the lighting conditions under which the inspections were done would have forced more time to be spent in visually locating and centering the rivets on the painted panel had a template and pencil probe been used. The inspections of 204 rivet sites on panels that simulated an aircraft fuselage took 53 minutes to complete. 
All results and comparisons reported are from single inspectors performing inspections over a large number of test specimens. This enables probability of detection curves to be fitted to each inspector - equipment combination. Inspector-to-inspector variations exist as is evidenced in comparing EC3 and EC4 results. The information on the Nortec -30 Eddyscan System presented here should be taken as reflective of capabilities when used by a well-trained inspector using setup procedures similar to those currently employed in field inspections. 


\section{Reference}

1. Spencer, Borgonovi, Roach, Schurman, and Smith, "Reliability Assessment at Airline Inspection Facilities, Vol II.: Protocol for an Eddy Current Inspection Reliability Experiment," DOT/FAA/CT-92/12, II.

2. Spencer, Floyd and Schurman, Don, "Reliability Assessment at Airline Inspection Facilities, Vol III.: Results of an Eddy Current Inspection Reliability Experiment" DOT/FAA/CT-92/12, III.(to be published spring '94) 


\section{DISTRIBUTION:}

1 Jan Achenbach

Northwestern University

Rm. 324 Catalysis Bldg., CTR QEFP

2137 Sheridan Road

Evanston, IL 60208-3020

1 Richard W. Anderson

Manager, Engineering Support

Federal Express

3101 Tchulahoma Road

Memphis, TN 38118-5413

2 Science Applications Int'l Corp.

Attn: Mike Ashbaugh John Wagner

2109 Air Park Road SE

Albuquerque, NM 87106

1 Terrance J. Bacola

Director, Maint. and Engr.

DHL Airways, Inc.

P. O. Box 75122

Cincinnati, $\mathrm{OH} 45275$

1 Roy Bailey

Delta Airlines

Hartsfield Atlanta Int'l Airport

Atlanta, GA 30320

1 George Barnes

Vice President, Maint. and Engr.

Hawaiian Airlines, Inc.

P. O. Box 30008

Honolulu Int'l Airport

Honolulu, HI 96820-0008

1 Stephen N. Bobo

U.S. DOT/VNTSC

Kendall Square

Cambridge, MA 02141

1 DOT/FAA

Engine and Propeller Directorate

Attn: A. L. Broz, ANE-105N

12 New England Exec. Pk.

Burlington, MA 01803

1 Richard Buzby

Director, Quality Control

Reeve Aleutian Airways, Inc.

4700 West Int'l Airport Rd.

Anchorage, AK 99502
1 Dale Chimenti

Iowa State University

FAA Center for Aviation Systems Reliability

Applied Sciences Complex II

1915 Scholl Road

Ames, IA 50011

2 Northwest Airlines, M/S C8840

Attn: Gary Clemmer, Dir., Inspection Jeff Register

5101 Northwest Dr.

St. Paul, MN 55111-3034

1 Toby Cordell

Wright Laboratory

Materials Directorate

SL/MLLP, W-PAFB, OH 45433-06533

1 FAA Northwest Mountain Region

Transport Airplane Directorate

Attn: Dayton Curtis, ANM-109

1601 Lind Ave. S.W.

Renton, WA 98055-4056

1 William Elliott, Chief

Structures Technology Branch

WR-ALC/TIED

Robins AFB, GA 31098-5149

1 Steve Erickson

Director, Maintenance \& Material

Air Transport Association

1301 Pennsylvania Ave. NW, Suite 1100

Washington, DC 20004-1707

3 FAA Technical Center

Aging Aircraft Program

Attn: Dave Galella, ACD-220

Chris Seher, ACD-220

Chris Smith, ACD-220

Atlantic City Airport, NJ 08405

1 Steve Gehl

EPRI

P. O. Box 10412

Palo Alto, CA 94303

1 Johnathan Goo

Aloha Airlines

P. O. Box 30028

Honolulu, HI 96820 
DISTRIBUTION (continued):

1 Don Hagemaier

Dept. 1L8, M.C. 36-14

Douglas Aircraft Co.

3855 Lakewood Blvd.

Long Beach, CA 90846

1 NASA LaRC

Attn: Joe Heyman, MS231

Hampton, VA 23665

1 Russell Jones

Inspection Foreman, NDT

US Air

P. O. Box 12346

Pittsburgh, PA 15231

1 William Keil

Region Airline Association

1101 Connecticut Ave. NW, Suite 700

Washington, DC 20036

1 Steve LaRiviere

Boeing Commercial Airplane Group

P. O. Box 3707, MS 9R058

Seattle, WA 96124-2007

1 Jess Lewis

FAA, Aircraft Certification Service

Continued Airworthiness Staff (AIR-107)

800 Independence Ave SW

Washington, DC 20591

1 Sarah MacLeod

Executive Director

Aeronautical Repair Station Association

121 North Henry Street

Alexandria, VA 22314

1 George A. Matzkanin

NDI Testing \& Analysis Center

415 Crystal Creek Drive

Austin, TX 78746

2 Trans World Airlines

Attn: Larry Brett, FAA/ATA Liaison \& QA Jim Morgan, Mgr, Inspection \& QA

P. O. Box 20126

Kansas City Int'] Airport

Kansas City, MO 64195-0126

1 Burl Nethercutt, MD23

American Airlines

P. O. Box 582801

Tulsa, OK 74158-2809
1 Don Nieser

OC-ALC/LACR

3001 Staff Drive, Suite 2AC489

Tinker AFB, OK 73145-3019

1 Richard L. Rohrig, Insp. Supervisor, NDT

Continental Airlines

8250 E. Smith Rd.

Denver, CO 80207

1 Ward D. Rummel

Martin Marietta Aerospace

8776 W. Mountainview L

Littleton, CO 80125

1 David Santoy

Director, Quality Control and QA

Evergreen Int'l Airlines

3850 Three Mile Lane

McMinnville, OR 97128

1 Bill Schultz

VP Engineering \& Maintenance

General Aviation Manufacturers Assoc.

1400 K Street NW, Suite 801

Washington, DC 20005

1 Bob Scoble

United Airlines

Manager, Aircraft Inspection

San Francisco International Airport

San Francisco, CA 94128

1 FAA Central Region

Small Airplane Directorate

Attn: Bob W. Sexton, ACE-102

601 East 12th St.

Kansas City, MO 64106

2 FAA

Attn: Fred Sobeck, AFS-330D

Les Vipond, AFS-302

800 Independence Ave. SW

Washington, DC 20591

1 Tom Swift

Federal Aviation Administration

AC Certification Office

3229 East Spring Street

Long Beach, CA 90806-2425 
DISTRIBUTION (continued):

1 Hajime Takeuchi

Dir., Eng., Program and Control United Airlines, SFOEG

San Francisco Int'l Airport

San Francisco, CA 94128

1 Bob Thomas, Director

Wayne State University

666 W. Hancock St.

Detroit, MI 48202

1 Bryan Vietrie

America West, M/S HG-2VC 4000 E. Skyharbor Blvd.

Phoenix, AZ 85034

1 Fred Workly

Manager, Maintenance Operations

National Air Transport Association 4226 King Street

Alexandria, VA 22302

1 William J. Miller

Correction Action (NDT)

Transport Air Canada

Centennial Towers

200 Kent Street

Ottawa, Ontario K1A ON8

CANADA
1 Philip Schnubb, Manager, NDT

Bradley Air Service

Carp Airport

Carp, Ontario K1A 1 L0

CANADA

1 MS0507 Ruth David, 2700

1 MS0615 Craig Jones, 2752

1 MS0615 David Moore, 2752

1 MS0615 Phil Walkington, 2752

1 MS0615 Bill Shurtleff, 2752

1 MS0616 Pat Walter, 2757

1 MS0616 Ken Harmon, 2757

1 MS0616 Dennis Roach, 2757

1 MS0829

$10 \quad$ MS0829

Robert Easterling, 12323

Floyd Spencer, 12323

Central Technical Files, 8523-2

MS9018

5 MS0899

1 MS0619

Technical Library, 7141

Technical Publications, 7151

10 MS0100
Document Processing, 7613-2

For DOE/OSTI 

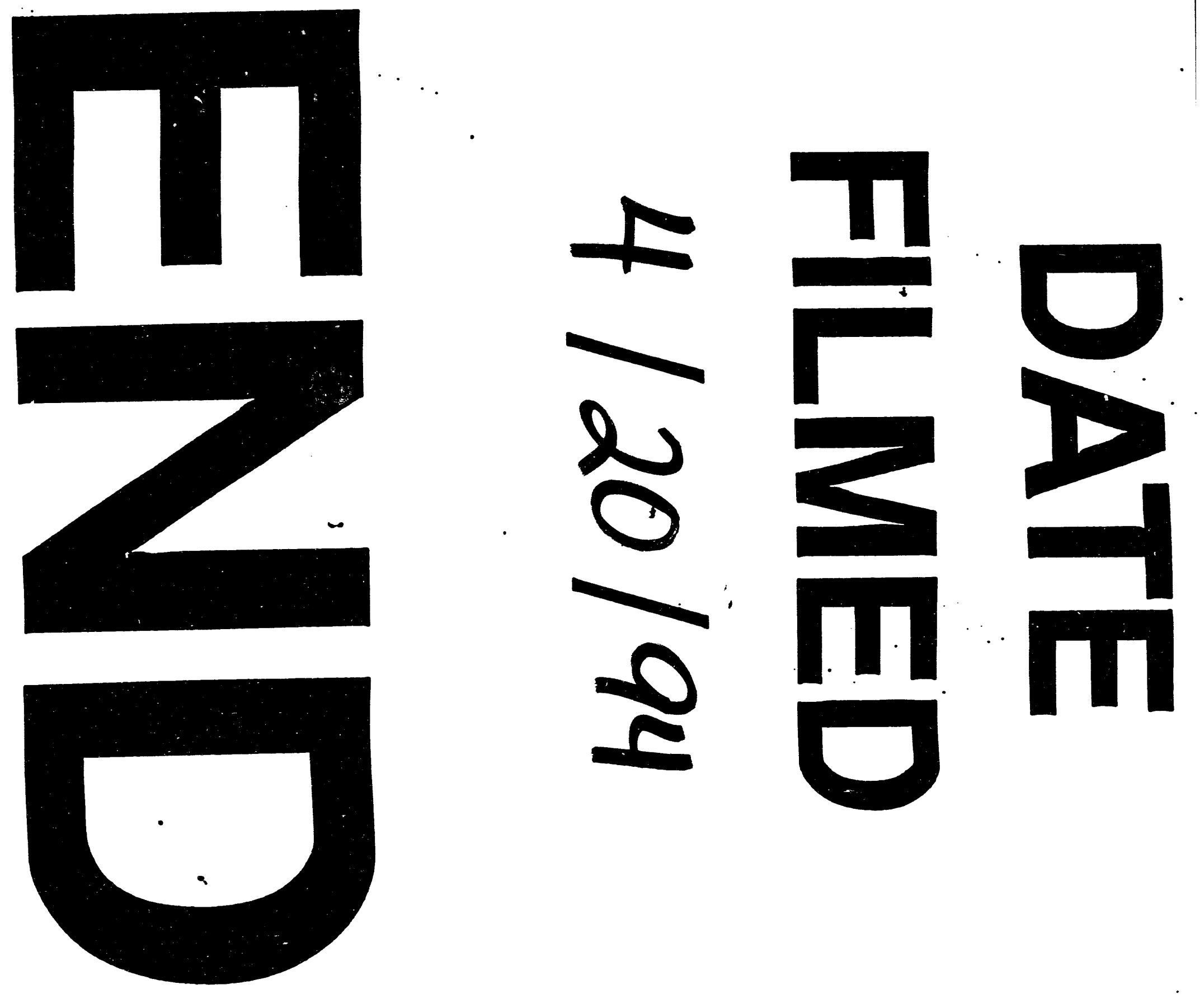
